\title{
Research on the Path and Countermeasures of Higher Vocational Teachers' Quality Improvement Promoted by Industry Research
}

\author{
Shengjin Wang, Ranran Zhou*, Jichuan Wang, Ying Chen \\ Shanghai Urban Construction Vocational College, Shanghai 201415, China
}

\begin{abstract}
Industrial research for the purpose of talent training is one of the important ways to change the current irrational structure of teachers in my country's higher vocational education system. Aiming at the current shortage of practical skills among teachers in higher vocational colleges, the necessity of industrial research to promote the development of higher vocational education in my country is analyzed. On this basis, a strategic framework for higher vocational teachers to conduct industrial research for the purpose of vocational talent training has been constructed from the five fundamentals which are industry needs, industry frontiers and development trends, work tasks and processes, professional standards, and professional qualifications.
\end{abstract}

Keywords: Higher Vocational Education; Industrial Research; Strategic Framework.

\section{Introduction}

"National Medium and Long-term Education Reform and Development Plan Outline (2010-2020)", "Decision of the State Council on Accelerating the Development of Modern Vocational Education" and "National Vocational Education Reform Implementation Plan" (referred to as Vocational Education Article 20) and other rigidities and document requirements, All require the integration of production and education and school-enterprise cooperation to achieve the fundamental goal of vocational education serving industrial development. Higher vocational colleges must cultivate higher education talents in line with industrial development, that is, the "professional chain serving the industrial chain." The logical premise for achieving this goal is that as the main body of educating colleges and universities and providers of vocational education products-higher vocational teachers must first have sufficient industrial knowledge and practical skills. However, the reality is far from the case. At present, teachers in higher vocational colleges, especially young and middle-aged teachers, possess a solid theoretical foundation under the disciplinary system training model, but the industry knowledge and related skills required for the training of higher vocational talents are extremely scarce. Enterprises have few connections, and are not familiar with and insensitive to market demand." This has become the biggest shortcoming restricting my country's higher vocational education. In addition, the deep-rooted training model of the discipline system, the system differences of enterprises and institutions, the single talent introduction model of the education system, and the difference in industry treatment have made the education sector (including higher vocational education) and the industry less integrated for a long time. Play with each other". In order to reverse this situation, people of insight began to pay attention to this issue. Vocational education research expert Professor Pan Jiajun strongly urged the professional construction of higher vocational education to "start with industrial research" [1].

\section{The Strategic Significance and Necessity of Industrial Research to Promote the Development of Higher Vocational Education}

At present, industry research has not attracted enough attention in the vocational education system, which can be corroborated by relevant research results. Taking CNKI as an example, if you search with the model of "topic word=vocational education" and "topic word=industry", you will find that 93\% of the top 100 core and CSSCI research documents are cited The research is about curriculum settings, school-enterprise cooperation, vocational education system, etc., while the comprehensive 
industry and vocational education-related research accounted for less than $6 \%$, and these few documents are mostly from the perspective of industrial transformation and upgrading. This research status can well reflect the "standards" problem that is detached from the reality of industrial production that is widespread in my country's higher vocational education research. The main reason for this phenomenon is that most of the teachers in higher vocational colleges graduated from higher education institutions in the subject system, and they directly engaged in higher vocational education without sufficient time of social and corporate practice. They have long been entrenched in discipline thinking and involuntarily guided the majority of higher vocational teachers follow the existing discipline-based talent training model, and deviate from the proper direction of vocational education. In addition, the current higher vocational education system, especially the evaluation model, does not support higher vocational teachers to conduct industrial research because it is difficult to produce scientific research results. To break through this bottleneck in the development of higher vocational education, it is necessary for higher vocational teachers to attach great importance to industrial research for the purpose of talent cultivation. Through industrial research to make up for the short legs of the majority of vocational teachers' lack of practical knowledge, combined with their own solid theoretical foundation, only in this way can the shortcomings of vocational teachers be changed and the "two legs" of practical skills and theoretical knowledge can be achieved smoothly.

\section{The Design of the Strategic Framework for Industrial Research to Promote the Development of Higher Vocational Education}

Based on this research purpose, this article will follow the characteristics and laws of vocational education, refer to the relevant theories and research results of existing vocational education, and combine the country's vision and planning for the development of vocational education and the reality of China's vocational education. Drawing lessons from the successful experience and models of higher vocational education in developed countries, try to build a strategic framework that aims at cultivating higher vocational talents and helps our country's higher vocational teachers to conduct industrial research.

Traditional discipline-based higher education is a typical ivory tower education. It uses cultural learning and theoretical research as a way. This kind of education model can be independent of actual production needs and purely pursue the construction of grand theory. This is not the case for higher vocational education. The "Outline of the National Medium and Long-term Educational Reform and Development Plan (2010-2020)" on the requirements of the modern vocational education system clearly stipulates that it is oriented to promote employment, and aims to cultivate "adaptation to changes in the economic development mode and "Industrial structure adjustment requirements" for industrial talents, require "professional setting and industrial demand docking", the layout of colleges and universities and the professional setting are more adapted to the needs of the economy and society. Therefore, vocational education expert Mr. Huang Daren proposed that the professional setting and the training of higher vocational talents should be carried out around the needs of the industry. Situ $\mathrm{Yu}$, Dean of Sichuan Engineering Vocational and Technical College, "where the industry develops, the school will follow up" [2].

Vocational education expert Professor Pan Jiajun pointed out on the integration of production and education that schools "should be more advanced in the development of the industry and be forwardlooking" [3]. It is based on this forward-looking thinking that the Shanghai Vocational College of Arts and Crafts where it is located has specifically included fashion trend prediction as the main content in the product modeling professional curriculum system and staged training goals, although this is very challenging. Professor Huang Daren also pointed out that when discussing the successful experience of "Project 211" and "Project 985", it is necessary to overcome the problems of "insufficient dynamic monitoring" and "identity fixation" that exist. When analyzing the construction of my country's modern vocational education system, Jiang Dayuan pointed out that the curriculum structure of vocational education should be based on the dynamics of the work process rather than 
the static state of general education based on the systemic knowledge of disciplines. This dynamic includes the future and trends of the industry, so he advocated higher vocational courses. The development should focus on what is implicit in the dynamic development [4].

Higher vocational teachers, especially those who come from the training model of the discipline system, lack of corporate work experience, or have insufficient work experience, through in-depth study of the real work tasks and work processes of industrial enterprises to maximize their approach and restore the enterprise Real work tasks and scenarios are an important means to get rid of textbook teaching and cultivate talents that truly meet the needs of enterprise development. Especially under the background that the subject-based teachers of higher vocational colleges account for the majority of the proportion, the integration of production and education and the slow progress of schoolenterprise cooperation, the majority of higher vocational teachers are advocated and required to cultivate talents, work tasks and work processes. Industrial research, which is the research object, has important overall significance for reversing the serious shortage of practical skills common to teachers in higher vocational colleges [5].

Occupational standards are the basic yardstick for measuring whether applied talents with technical skills meet the needs of industrial development, and they are also the benchmarks and guidelines for the training of higher vocational education talents. Scientific, reasonable, concise, and easy-to-operate professional standards have a programmatic guiding role in improving the quality of higher vocational talents. Higher vocational teachers' in-depth understanding and research on professional standards will help teachers understand and grasp the depth of teaching content, and make teaching content more in line with the actual needs of industrial development.

At present, one of the reasons for the actual development of backward teaching industry that is common in higher vocational education is that higher vocational teachers are not clear about the professional standards that are compatible with their majors. This easily leads to the content of the teaching being too strong or too theoretical. Empty, or lag the actual production. Therefore, the "Decision of the State Council on Accelerating the Development of Modern Vocational Education" clearly stipulates in the overall requirements that the content of professional courses and professional teaching standards must match the professional standards and form a linkage mechanism; the "National Vocational Education Reform Implementation Plan" (vocational education Article 20) Also requires standardization as a breakthrough to lead the development of vocational education.

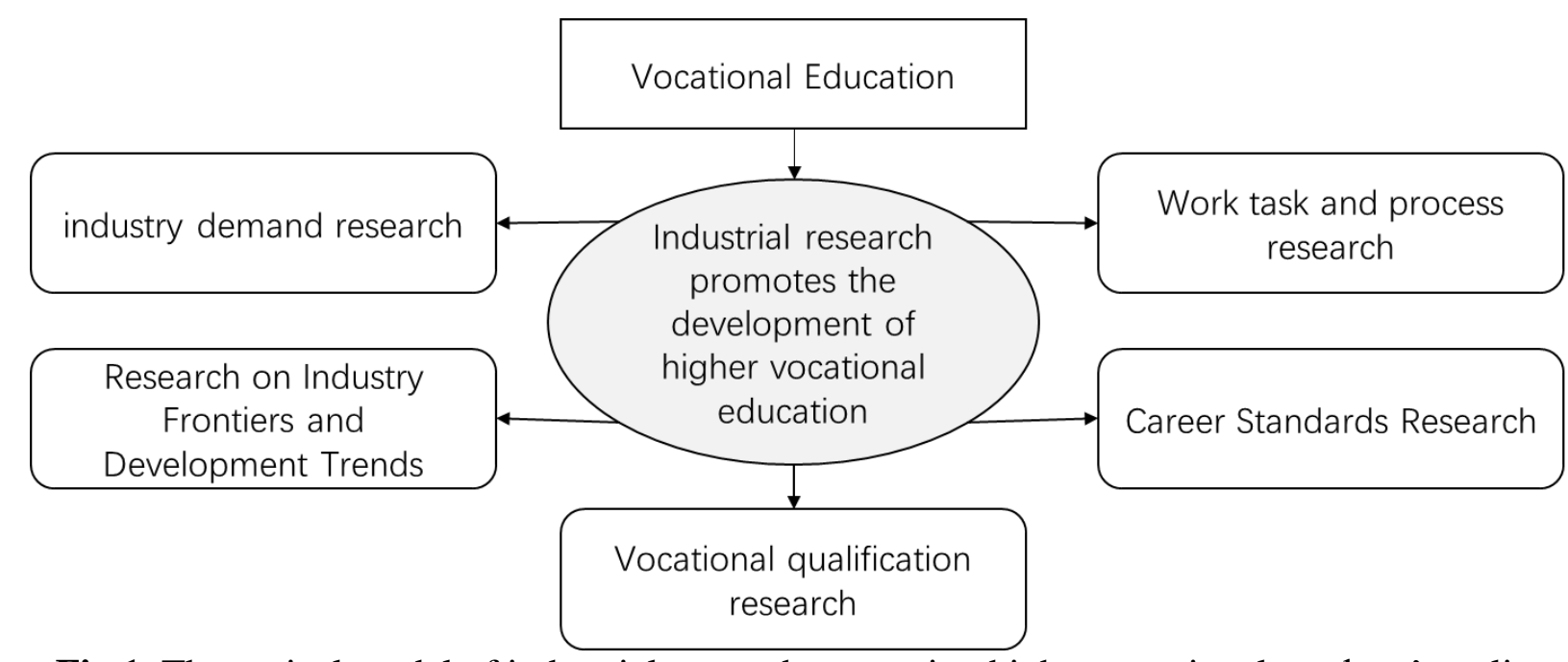

Fig 1. Theoretical model of industrial research promoting higher vocational teachers' quality

\section{Summary}

At present, my country's higher vocational education is at a critical stage of transformation and breakthrough. It is a difficult problem that all sectors of society are paying attention to explore a higher vocational talent training model and path suitable for my country's national conditions. As one 
of the main bodies of talent training, vocational teachers, how to improve their industrial knowledge and practical ability is an urgent task that the majority of vocational teachers need to solve. Industry research helps to change the current lack of industry knowledge and practical skills that are common in higher vocational teachers, and can effectively improve the practical skills of higher vocational teachers. This is an important promotion for the real implementation of the deep integration of my country's higher vocational education and industrial practice.

\section{References}

[1] Pan Jiajun. Research on the expected trend and related issues of the development of vocational education in the new era [J]. Research on Vocational Education Development, 2019(01):19-23.

[2] Huang Daren. Looking forward to the future of higher vocational education [J]. Journal of National Academy of Educational Administration, 2012(07): 3-8.

[3] Jiang Dayuan. Success stories, nurturing successful thoughts-written to Nanjing Higher Vocational School "Dual System in China"[J]. Jiangsu Education, 2012(27): 15-16.

[4] Pan Jiajun. Rethinking about the integration of industry and education[J]. China Training, 2017(18): 31 33.

[5] Jiang Dayuan. On the Systematic Design of Higher Vocational Education Curriculum--Interpretation of the Systematic Curriculum Development of Work Process [J]. China Higher Education Research, 2009 (04): 66-70. 